\title{
Erratum: The nucleotide binding dynamics of human MSH2-MSH3 are lesion dependent
}

Barbara A L Owen, Walter H Lang \& Cynthia T McMurray

Nat. Struct. Mol. Biol. 16, 550-557 (2009); published online 19 April 2009; corrected after print 18 May 2009

In the version of this article initially published, the first sentence referring to Figure $2 \mathrm{c}$ (page 552, first paragraph) was incorrect. It should read: "To further test the stochastic binding of nucleotides, we simultaneously added a constant amount $(5 \mu \mathrm{M})$ of labeled $\mathrm{ADP}\left(+\mathrm{Mg}{ }^{2+}\right)$ and increasing concentrations of unlabeled AMP-PNP $\left(+\mathrm{Mg}^{2+}\right)$ to MSH2-MSH3 (Fig. 2c, left)." The error has been corrected in the HTML and PDF versions of the article.

\section{Corrigendum: Three-dimensional reconstruction of the} Shigella T3SS transmembrane regions reveals 12-fold symmetry and novel features throughout

Julie L Hodgkinson, Ashley Horsley, David Stabat, Martha Simon, Steven Johnson, Paula C A da Fonseca, Edward P Morris, Joseph S Wall, Susan M Lea \& Ariel J Blocker

Nat. Struct. Mol. Biol. 16, 477-485 (2009); published online 26 April 2009; corrected after print 18 May 2009

In the version of this article initially published, the incorrect accession number for EM map deposition was provided. The correct accession number for the data deposited in EmDep is EMD-1617. The error has been corrected in the HTML and PDF versions of the article. 